Tomoki Nishiyama MD PhD, Kazuo Hanaoka MD PhD

\title{
A traumatic asphyxia in a child
}

Purpose: Traumatic asphyxia in a child is rare and the pathophysiology is different from that occurring in an adult. We report a case of traumatic asphyxia in a child who recovered without specific treatment, even though chest and abdominal compression was severe.

Clinical features: A three-year-old boy $(14.2 \mathrm{~kg}$ ) was run over by the rear wheel of a Jeep. He was under the tire for about three minutes and then was transferred to our hospital. When he arrived, he was lethargic with Glasgow Coma Scale of E3V4M6 (coma score of 13). He was cyanotic in his face and had a tire mark from the left shoulder to the right abdomen, petechia on the head, face, conjunctiva and chest, oral bleeding, and facial edema. Serum concentrations of liver enzymes were increased and microhematuria was detected. However, no injuries were seen in the brain, eye, chest, or abdomen. Cyanosis disappeared in a few hours. Facial and thoracic petechia disappeared in three days and that of the conjunctiva in five days. He was discharged from hospital on the I 3th day without any disturbances.

Conclusion: We present a three-year-old boy with traumatic asphyxia. He had no complications although he received severe thoraco-abdominal compression by a Jeep.

Objectif : L'asphyxie traumatique, rare chez l'enfant, présente une physiopathologie différente de celle de l'adulte. Nous citons le cas d'un enfant qui a subi une asphyxie traumatique et qui a récupéré sans traitement particulier, même avec une compression thoracique et abdominale sévère.

Éléments cliniques : Un garçon de 3 ans, ( 14,2 kg) a été écrasé sous une roue arrière d'un Jeep. II s'est retrouvé sous le pneu pendant environ 3 min et a été conduit, par la suite, à notre hôpital. À son arrivée, il était léthargique et présentait une cote de E3V4M6 à l'échelle de Glasgow (score de coma de 13). Son visage était cyanosé et il avait une marque de pneu allant de l'épaule gauche à la partie droite de l'abdomen, des pétéchies à la tête, au visage, sur la conjonctive et la poitrine, un saignement buccal et un œdème facial. Les concentrations sériques d'enzymes hépatiques étaient augmentées et on a détecté une microhématurie. Cependant, aucune lésion n'a été observée au cerveau, aux yeux, au thorax ou à l'abdomen. La cyanose est disparue en quelques heures, les pétéchies faciales et thoraciques en trois jours et celles de la conjonctive en cinq jours. L'enfant a pu quitter l'hôpital au I3e jour et ne présentait aucun trouble.

Conclusion : Nous avons cité le cas d'un enfant de 3 ans qui a souffert d'asphyxie traumatique. II n'a pas présenté de complications même s'il a subi une sévère compression thoraco-abdominale.

From the Department of Anesthesiology, the University of Tokyo, Faculty of Medicine, 7-3-1, Hongo, Bunkyo- ku, Tokyo, 113-8655 Japan. Address correspondence to: Tomoki Nishiyama MD PhD, 3-2-6-603, Kawaguchi, Kawaguchi-shi, Saitama, 332- 0015, Japan. Phone: 81-35800-8668 (Dept.), 81-48-258-4911 (home); Fax: 81-3-5800-8938 (Dept.), 81-48-258-4911 (home); E-mail: nishiyam@ims.u-tokyo.ac.jp Accepted for Publication July 27, 2000. 
$\mathrm{T}$

RAUMATIC asphyxia is a rare syndrome caused by chest compression and was first described by Ollivier. ${ }^{1}$ Clinically, it is characterized by subconjunctival hemorrhage, facial edema, cyanosis, and petechia on the upper chest and face. ${ }^{1}$ Traumatic asphyxia in children differs, in pathophysiological aspects, from that seen in adults because of the greater elasticity of the thorax in children. ${ }^{2}$ We report a child with traumatic asphyxia who recovered without specific treatment, even though chest and abdominal compression was severe.

Case report

A three-year-old boy (14.2 kg) with a history of asthma was run over by the rear wheel of a Jeep. He was under the rear tire for about three minutes and cried. He was taken immediately to our hospital by ambulance and received no treatment other than oxygen by face mask before reaching the hospital. On arrival, he was lethargic with Glasgow Coma Scale of E3V4M6 (coma score of 13). His blood pressure was $80 / 50 \mathrm{mmHg}$, heart rate 108 beats. $\mathrm{min}^{-1}$, and respiratory rate 32 breaths. $\mathrm{min}^{-1}$. He had facial cyanosis and had a tire mark from the left shoulder to the right abdomen, petechia on the head, face, conjunctiva and chest, oral bleeding, and facial edema (Figure). Blood gas analysis just after he was brought to the intensive care unit was: $\mathrm{pH} 7.38, \mathrm{PaCO}_{2} 40.4 \mathrm{mmHg}, \mathrm{PaO}_{2} 370.3 \mathrm{mmHg}$, base excess $-1.3 \mathrm{mMol} \cdot \mathrm{L}^{-1}$ breathing $5 \mathrm{~L} \cdot \mathrm{min}^{-1} 100 \%$ oxygen by a face mask. Increased white blood cell count $\left(19,600\right.$ counts $\left.\cdot \mathrm{mm}^{-3}\right)$, aspartate aminotransferase (AST, $430 \mathrm{IU} \cdot \mathrm{L}^{-1}$ ) and alanine aminotransferase (ALT, $\left.246 \mathrm{IU} \cdot \mathrm{L}^{-1}\right)$ were seen on blood examination. Microhematuria was detected. Cervical, chest and abdominal X-ray and echography showed no injuries. Hemorrhage and edema were not observed in the brain by computed tomography. Ophthalmological examination, including fundoscopy, revealed no abnormalities.

$\mathrm{He}$ was observed in the intensive care unit without specific treatment except for maintenance fluid and monitoring of arterial blood pressure, electrocardiogram and central venous pressure. The cyanosis disappeared in a few hours. Facial and thoracic petechia disappeared in three days and that of the conjunctiva in five days. His consciousness gradually improved and he became alert on the fourth day. Serum concentrations of AST and ALT decreased to normal on the seventh day (28 IU.L $\mathrm{L}^{-1}$ AST and 27 IU.L $\mathrm{L}^{-1}$ ALT). He complained of right lumbar and leg pain on the sixth day and X-ray showed a fracture of the right iliac bone for which no treatment was necessary. He was transferred to the ward on the second day and was discharged from the hospital on the 13th day without any disturbances.

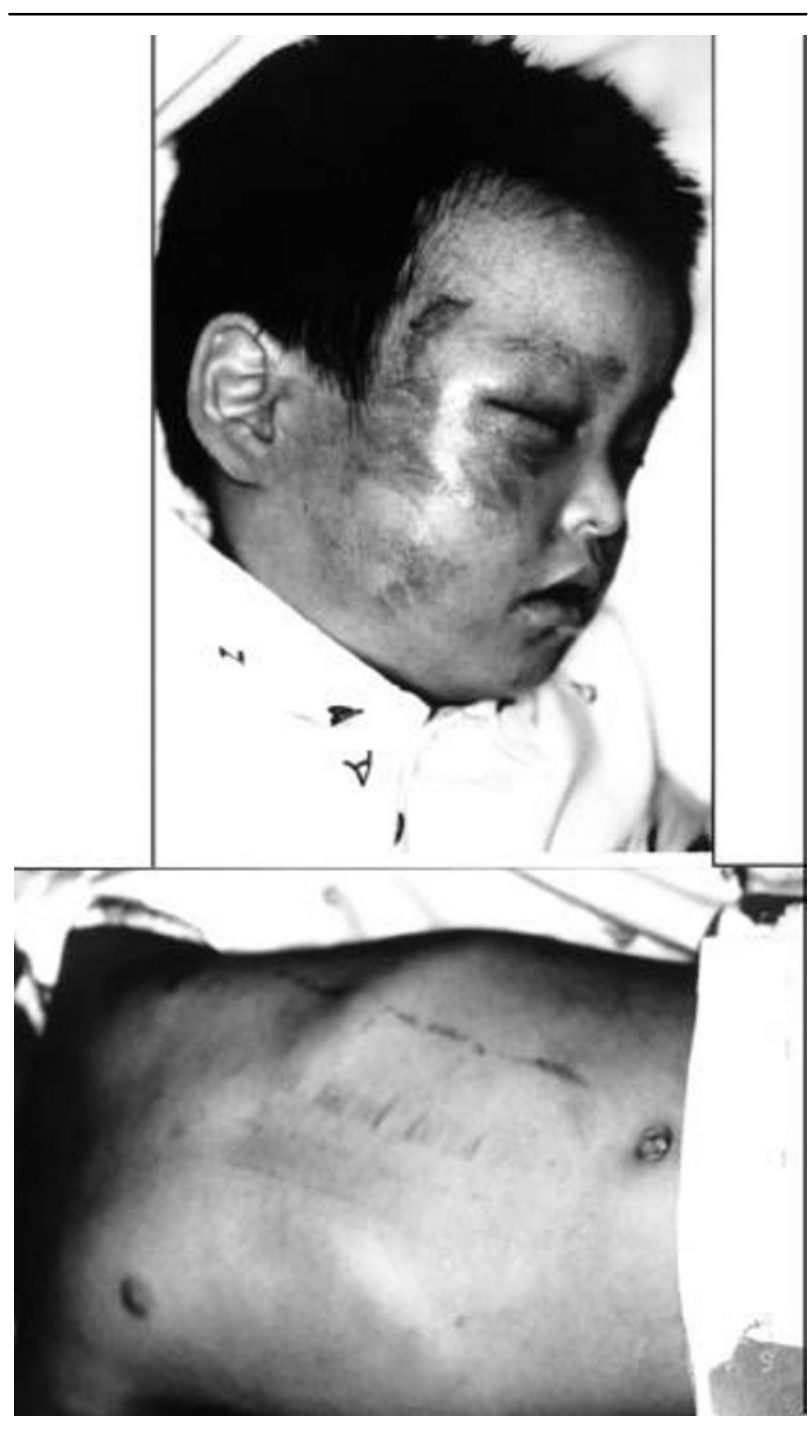

FIGURE Face (upper) and body (lower) of the child with traumatic asphyxia. Cyanosis, petechiae, and edema are seen in his face. A tire mark is seen on his body.

Discussion

Cases of traumatic asphyxia are mainly a consequence of motor vehicle crashes as in the present case. Other causes include heavy machines, furniture and, rarely, deep sea diving, epileptic seizures and asthma. ${ }^{1}$ The typical range of the duration of compression is between two and five minutes. ${ }^{3}$ The duration and the weight of compression affect the outcome following traumatic asphyxia. Considerable weight can be tolerated for a short period, whereas a comparatively modest weight applied for a longer period may result in 
death. ${ }^{4}$ In animal experiments, no animal survived compression by five times its own weight for longer than 10 min. ${ }^{5}$ This $14.2 \mathrm{~kg}$ child was under a vehicle with a weight of more than $2000 \mathrm{~kg}$ (500 kg per wheel), which was about 150 times (37.5 times if considering the weight per wheel) of his body weight, for about three minutes. Although this resulted in considerable compression, he recovered without any sequella perhaps due to the short duration of the compression and due to the elasticity of his chest. The details of the compression were not known. In considering the tire mark the wheel might not stay on one part but moved on the body for three minutes and this may be another reason why the damage was so light. One more important factor influencing the outcome may be the orientation of the compression. In this case, the tire mark was predominantly over the left upper abdomen and left chest. This might spare the constrictions of cardiac output and venous return such that the child's neurological status on arrival was very good. If the wheel had rolled onto the midchest at right angles to the long axis of the body, the result might have been worse.

Petechia were seen only on the upper part of the body. Petechia formation is thought to occur because blood is forced out of the right atrium through the valveless innominate and jugular veins into the head and neck by positive pressure transmitted to the mediastinum from the compressed chest or upper abdomen. ${ }^{6}$ This sudden increased pressure in small venules and capillaries causes rapid dilatation and minute hemorrhages, producing the petechia. Due to the same mechanisms, visual disturbances occur in some cases. ${ }^{7}$ Therefore, opthalmological follow up is important. The present case had no opthalmological abnormalities revealed by fundoscopy.

The reason why cyanosis, petechia and edema are confined to the upper part of the body may be because the lower part of the body is protected from the elevated venous pressure by a series of valves. ${ }^{8}$ Alternatively, increased airway pressure may compress or obliterate the inferior vena cava to protect the lower part of the body. ${ }^{9}$ Although cyanosis, petechia and edema were seen only in the upper part of his body, serum concentrations of liver enzymes increased and hematuria was observed in the present case. These abnormalities might have resulted from direct abdominal compression, as evidenced by the tire mark on the abdomen, and/or increased venous pressure transmitted to liver and kidney. He had no radiographic liver or renal injury necessitating surgical treatment.

The boy was lethargic but recovered in four days. Lethargy have been due to hypoxia or brain edema by chest compression but no apparent edema was detected by computed tomography.

Traumatic asphyxia may also be complicated by serious thoracic injuries including pneumothorax, hemothorax, rib fractures or flail chest, and mediastinal injuries, and head injuries. ${ }^{10}$ Even with those complications, the mortality rate is usually low in children. ${ }^{10}$ This child was also fortunate not to have incurred more severe chest trauma, given the mechanism of elastic chest cage.

At first we did not diagnose his right iliac fracture. The boy had no complaints, perhaps due to bed rest and depressed consciousness, and because it was difficult to confirm the fracture line of a small child on plain pelvic radiographs. Examining physicians should be aware that subtle associated injuries may be present, especially in small children with disturbed consciousness.

Usually the prognosis of traumatic asphyxia is good with no long-term disability when the patients have no complicated injuries, ${ }^{6,8}$ except that visual disturbance may continue.? The child in the present case had the potential for serious injury, but recovered without any impairment. In managing traumatic asphyxia, it is important to pay particular attention to detect and treat complicating injuries including opthalmological examination.

Acknowledgment

We would like to thank Professor Chingmuh Lee MD, Department of Anesthesiology, University of California Los Angeles School of Medicine, for his helpful comments.

\section{References}

1 Lowe L, Rapini RP, Johnson TM. Traumatic asphyxia. J Are Acad Dermatol 1990; 23: 972-4.

2 Meller JL, Little AG, Shermeta $D W$. Thoracic trauma in children. Pediatrics 1984; 74: 813-9.

3 Fred HL, Chandler FW. Traumatic asphyxia. Am J Med 1960; 29: 508-17.

4 Compbell-Hewson G, Egleston CV, Cope AR. Traumatic asphyxia in children. J Accid Emerg Med 1997; 14: 47-9.

5 Furuya $\Upsilon$. Experimental traumatic asphyxia - grades of thoracic compression and mortality. Igaku Kenkyu 1981; 51: 117-9.

6 Gorenstein L, Blair GK, Shandling B. The prognosis of traumatic asphyxia in childhood. J Pediatr Surg 1986; 21: 753-6.

7 Baldwin GA, Macnab AJ, McCormick AQ. Visual loss following traumatic asphyxia in children. J Trauma 1988; 28: 557-8.

8 Landercasper J Cogbill TH. Long-term followup after traumatic asphyxia. J Trauma 1985; 25: 838-41. 
9 Thompson A Jr, Illescas FF, Chiu RC-J. Why is the lower torso protected in traumatic asphyxia? A new hypothesis. Ann Thorac Surg 1989; 47: 247-9.

10 Sariban H, Abes M, Akyazici R, et al. Traumatic asphyxia in children. J Cardiovasc Surg 1997; 38: 93-5. 